\title{
The State of Job Burnout Symptoms and the Difference among Police: an Empirical Research
}

\author{
Zhenxing Gong \\ School of Business \\ Liaocheng University \\ Liaocheng, China \\ zxgong163.com
}

Shuo Wang

School of Business

Liaocheng University

Liaocheng, China

37582528qq.com

\author{
Haoyun $\mathrm{Yu}$ * \\ School of Business \\ Liaocheng University \\ Liaocheng, China \\ 1686926382qq.com \\ *Corresponding author
}

\author{
Zanzan Zhao \\ School of Business \\ Liaocheng University \\ Liaocheng, China \\ 1052887341qq.com
}

\begin{abstract}
To understand the job burnout of policemen, in order to provide a practical basis for preventing and intervening police job burnout. A Chinese Job Burnout Questionnaire ( $\mathrm{Li}$ Yongxin) was used to investigate 363 policemen in Liaocheng, Shandong Province. On the whole, the detection rate of police burnout is $61.5 \%$; From demographic variables, The difference between male and female policemen in dehumanizing dimension is very significant $(P<\mathbf{0 . 0 0 1})$, There are significant differences among different age police in all dimensions, There are significant differences among different police officers in all dimensions, The police aged 6-10 years have the highest degree of humanization, There are significant differences in the three dimensions of policemen of different degrees. Job burnout is common among police in Liaocheng, and there are different degrees of job burnout among different groups of police.
\end{abstract}

Keywords-Police; job burnout; investigation

\section{INTRODUCTION}

The concept of job burnout was first proposed by Freudenberger in 1974[1], A large proportion of office workers have varying degrees of job burnout. Job burnout is a comprehensive symptom of physical and mental exhaustion and energy exhaustion caused by long-term work stress, it includes three dimensions: emotional exhaustion, dehumanization and personal accomplishment [2]. Emotional exhaustion reflects individual stress dimensions, It describes the overdraft of physical and mental resources that individuals feel effective, Showing no energy, fatigue and so on; De personalization reflects the dimension of interpersonal situation, Describes an individual facing a service object or job with a negative, indifferent, or extremely evasive attitude, Showing irritability, negativity, lack of emotional input and so on; The loss of personal accomplishment reflects the self-evaluation

This research was supported by grants from the National Natural Science Foundation Youth Science Fund of China (71801120), the Ministry of Education of Humanities and Social Science Research youth fund project (18YJC630038), Shandong Social Science Planning Fund Youth Program (18DGLJ02) dimension of job burnout, Describing individuals who feel incompetent and inefficient, show low morale and lack of achievement[3]. In the three dimensions, emotional exhaustion is the most widely reported and thoroughly analyzed, there are many research reports that, Emotional exhaustion represents the core dimension of job burnout (Maslach C, Jackson S E\&Leiter M P, 1997) [4].

Public security work is characterized by high stress, high pressure and high risk. It is also a vulnerable and high-risk group of job burnout. Police job burnout will not only cause the physical and psychological problems of the police, but also bring many problems to the efficiency and quality of the whole public security organ and the long-term stability of the whole society. Therefore, it is necessary to study police job burnout. Through the actual investigation to understand the situation of police job burnout, I hope it will be helpful to prevent and alleviate police job burnout.

\section{A. Research object}

To applied cluster sampling method, A questionnaire survey was conducted among the working police in Liaocheng Public Security Bureau of Shandong province. A total of 390 questionnaires, Reclaim 381 copies, Rate of recovery $97.69 \%$. of which 363 valid questionnaires were valid questionnaires was $95.28 \%$. There were 290 male policemen in the study, accounting for $79.9 \%$; 73 policewomen, accounting for $20.1 \%$. The subjects were divided into five groups by age:(1) 46 persons aged 25 and below, accounting for 12.7\%;(2) 26-30, 123, 33.9\%;(3) 31-35,75,20.7\%;(4) 36-40,57,15.7\%;(5) 62 persons aged 41 and over, accounting for $17.1 \%$. The subjects were divided into three groups according to their educational background:(1) High school, technical secondary school and the following 54, accounting for 14.9\%;(2) Specialist 144, accounting for 39.7\%;(3) Undergraduate and above 165, accounting for $45.5 \%$. 


\section{B. Measuring tool}

The questionnaire required in this study included personal basic information and Job Burnout Questionnaire.

The personal statistics table includes gender, age, marital status, police type, age and education level.

The job burnout questionnaire was based on the Chinese job burnout questionnaire compiled by Professor Li Yongxin. There were 15 items in the questionnaire, which included three dimensions: emotional exhaustion, dehumanization and reduced personal accomplishment Each dimension was 5 items, and the questionnaire was scored by 7 grades, with "1" as "completely inconsistent" and "7" as "completely consistent". From "1" to "7", the conforming degree is from low to high. Among them, the scores of sense of achievement were all reversed. Principal Component Analysis (PCA) was used to analyze the three factors. The explanatory rate of cumulative variance was $58.729 \%$. The internal consistency coefficients of emotional exhaustion, dehumanization and personal accomplishment were $0.860,0.839$ and 0.714 , The internal consistency of the total scale was 0.841, which was significantly higher than the recommended value of 0.70 , indicating that the questionnaire had good conceptual validity and internal consistency reliability

\section{Measuring methods and procedures}

Cluster sampling was carried out from Liaocheng city and counties (cities and districts) in Shandong province. Questionnaires were conducted by means of centralized study or meeting time. Before filling in the questionnaire, it was stated that all the data were limited to scientific research, and the subjects were asked to answer the questionnaire according to the instructions for 20 minutes. After the questionnaires were returned, invalid questionnaires were deleted. The data of the survey were analyzed by SPSS12.0

\section{RESEARCH RESULTS}

\section{A. Job burnout of different genders}

TABLE I. ST ATISTICS ON JOB BURNOUT OF DIFFERENT POLICEMAN GENDERS=363)

\begin{tabular}{clccccc}
\hline dimension & Sex $\boldsymbol{N}$ & Mean & SD & SE & T & P \\
\hline \multirow{2}{*}{ Emotional exhaustion } & Man 290 & 18.4310 & 8.07815 & 0.47437 & 1.594 & 0.112 \\
& Woman 73 & 16.7945 & 6.80882 & 0.79691 & & \\
\hline \multirow{2}{*}{ To be humanized } & Man 290 & 11.9414 & 6.45077 & 0.3788 & $3.857^{* * *}$ & 0.000 \\
& Woman 73 & 9.5205 & 4.27561 & 0.50042 & & \\
\hline \multirow{2}{*}{ Low personal accomplishment } & Man 290 & 14.5448 & 5.52375 & 0.32437 & 1.445 & 0.149 \\
& Woman 73 & 13.5205 & 4.93601 & 0.57772 & & \\
\hline
\end{tabular}

Notes: $* \mathrm{P}<0.05, * * \mathrm{P}<0.01, * * * \mathrm{P}<0.001$

As can be seen from table 1, on the three dimensions of job burnout, the average score of policewomen is lower than that of male policemen. T-test results showed that there was no significant difference between male and female policemen in the dimensions of emotional exhaustion and personal accomplishment; in the dimension of depersonalization, male policemen scored higher than female policemen, and the difference between male and female policemen was very significant $(\mathrm{P}<0.001)$.

\section{B. Job burnout of policemen at different ages}

TABLE II. STATISTICS ON JOB BURNOUT OF POLICEMEN AT DIFFERENT AGES(N=363)

\begin{tabular}{|c|c|c|c|c|c|c|}
\hline Variable & $\begin{array}{l}25 \text { years old and } \\
\text { below }(n=46)\end{array}$ & $\begin{array}{l}26-30 \\
(n=123)\end{array}$ & $\begin{array}{l}31-35 \\
(n=75)\end{array}$ & $\begin{array}{r}36-40 \\
\quad(n=57)\end{array}$ & $\begin{array}{c}41 \text { years old or } \\
\text { above }(n=62)\end{array}$ & $\boldsymbol{F}$ \\
\hline Emotional exhaustion & $15.63 \pm 8.62$ & $18.81 \pm 7.87$ & $19.17 \pm 8.65$ & $16.35 \pm 7.36$ & $18.84 \pm 6.17$ & $2.628 *$ \\
\hline To be humanized & $9.50 \pm 5.24$ & $12.41 \pm 7.01$ & $11.77 \pm 6.04$ & $10.26 \pm 5.48$ & $11.46 \pm 6.15$ & $2.558^{*}$ \\
\hline $\begin{array}{c}\text { Low personal } \\
\text { accomplishment }\end{array}$ & $14.36 \pm 6.49$ & $14.86 \pm 5.48$ & $14.37 \pm 4.77$ & $12.98 \pm 5.50$ & $14.47 \pm 5.05$ & 1.200 \\
\hline
\end{tabular}

From Table 2, we can see that there are differences in emotional exhaustion and depersonalization in the three dimensions of job burnout among policemen of different ages. Multiple comparisons showed that there were significant differences in the emotional exhaustion dimension between policemen under 25 years old and policemen over 25 years old, and in the dehumanization dimension, there were significant differences between policemen under 25 years old and policemen between 26 and 30 years old.

\section{Job burnout of police officers with different educational} levels

TABLE III. STATISTICS ON JOB BURNOUT OF POLICE OFFICERS WITH DIFFERENT EDUCATIONAL LEVELS(N=363)

\begin{tabular}{cccc}
\hline Variable & $\begin{array}{c}\text { High school, technical secondary school and } \\
\text { below(n=108) }\end{array}$ & $\begin{array}{c}\text { Junior } \\
\text { College(n=104) }\end{array}$ & $\begin{array}{c}\text { Bachelor degree or } \\
\boldsymbol{a b o v e}(\mathbf{n}=77)\end{array}$ \\
\hline Emotional exhaustion & $18.69 \pm 6.81$ & $16.65 \pm 7.51$ & $19.18 \pm 8.31$ \\
\hline To be humanized & $13.50 \pm 5.92$ & $12.38 \pm 6.70$ & $9.98 \pm 5.01$ \\
\hline $\begin{array}{c}\text { Low personal } \\
\text { accomplishment }\end{array}$ & $16.54 \pm 6.10$ & $14.77 \pm 5.33$ & $13.24 \pm 5.01$ \\
\hline
\end{tabular}


From Table 3, we can see that there are very significant differences in the three dimensions of job burnout among policemen with different educational levels. Multiple comparisons show that in the dimension of emotional exhaustion, there are very significant differences between the policemen with education level above undergraduate and the policemen with education level below junior college; in the dimension of dehumanization, there are very significant differences between the policemen with education level above undergraduate and the policemen with education level below junior college, senior high school, secondary school and junior college. There is a significant difference in the level of personal accomplishment between the different educational levels of the police.

\section{DISCUSSION}

\section{A. Overall situation of Police Job Burnout}

A total of 363 questionnaires were validly collected in this study, 223 of them were found to have job burnout symptoms, with a total detection rate of $61.4 \%$. Job burnout was prevalent in the police, which was almost the same as that of the medical staff studied by Li Yongxin, but significantly lower than that of the teachers. Teachers, doctors and nurses, and policemen are all the most tired people in the current society[5], The reason why the detection rate of job burnout is not so serious in general is closely related to the objective situation of the local police. First of all, in recent years, the public security organs that have passed the civil service enrollment examination have attracted a lot of intellectual talents with rich theory and wide knowledge, so as to lay a good human foundation for strengthening the police through science and technology. Secondly, in order to make up for the shortage of police force, the Public Security Bureau and personnel departments jointly recruited a large number of grass-roots policemen, and through the continuous optimization of bureau organs, the police force subsided, to a certain extent, alleviated the shortage of police force. Thirdly, public security leaders, political engineering and office leaders continue to learn advanced management methods to implement the humanized management, and public security social status is higher, wages are not low, can be paid in full and on time. Finally, although the police are facing greater professional pressure, Shandong people's style of life is simple, the level of support for the police is high, and the local news media can do a good job in police publicity, so that the police have a good external support for the bad situation

\section{B. The influence of demographic variables on Job Burnout of policemen}

In addition to investigating the overall situation of job burnout in police groups, this paper will study the sample according to different demographic variables.

Gender factors. In the dimension of emotional exhaustion and personal accomplishment, the average scores of female policemen are lower than those of male policemen, but the difference is not significant; in the dimension of dehumanization, the average scores of female policemen are lower than that of male policemen, the difference is very significant, which shows that female policemen have lower job burnout than male policemen, there are many reasons: first, male policemen except Besides work, they also have to support their families. The social impact they face is more intense. The conflicts between work and family and the psychological pressure they bear are greater. The emotional exhaustion resulting from this is more serious than that of the female policemen. Secondly, because of the professional characteristics of the policemen themselves, the female policemen are mostly concentrated in the departments with less pressure, while the male policemen are more out-of-town and in danger. There are many tasks such as more dangerous, more physical strength, dealing with contradictions and disputes, so long-term facing the dark side of society, contact with all kinds of violence or vicious events, a long time, increased their tendency to make a negative view of things, deepened the degree of dehumanization; third, female police have a unique female Rich, delicate emotional characteristics and motherly-like emotional roles make it difficult for policewomen to be indifferent to their work partners. Women policemen tend to separate their lives from their work, unlike men who tend to value their careers so much that women policemen are less likely to experience the pressures of life-at-work conflicts; for traditional reasons, the gender roles of male policemen are emphasized. Strength, independence and other characteristics, the high pursuit of achievement is easy to make male policemen in the face of pursuit or expectations of failure more likely to suppress their true feelings.

Age factors, There is no linear relationship between the three-dimensional degree of police job burnout and age. The development of police job burnout is a fluctuating process and shows different trends at different stages. The development of police job burnout is closely related to the development of the police themselves. There are differences in the focus of attention among policemen of different ages, which inevitably leads to differences in their perceptions of work. Young police officers aged 25 and younger are still in a period of vigorous development, vigorous in their work, full of enthusiasm and enthusiasm for responsibility as a people's police officer. As the backbone of the police force, young and middle-aged policemen, aged 26-35, bear more responsibilities, and work in a high load for a long time, which requires them to contact many dark sides of society. Initial enthusiasm and enthusiasm are gradually stripped away, and most of this year. Police officers of all ages are married, having children after marriage and the elderly need to be brought up, and work is easy to conflict, physical and psychological fatigue also arises. In addition, in the 1990s, the entrance of public security organs was too wide, resulting in uneven quality of the police, especially through self-study and amateur study to obtain academic qualifications, the level is lower, especially in the face of some of the current assessment, it is difficult to cope with freely, great mental pressure, personal accomplishment is not high. Many middle-aged policemen aged 36-40 are already the backbone and leaders of the police force. They have strong independence and autonomy in their work. Many of them have been leaders of some departments. They have greatly improved their work influence and work influence. They are experienced and have accumulated a certain amount of experience both at work and in dealing with stress, and have entered the professional maturity period. The policemen aged 40 and over will have little room for improvement because of their age, 
especially for the old policemen aged 50 or so who feel uneven when they come to retire and feel helpless, so there is an upward trend of emotional exhaustion and dehumanization rebound.

Educational factors. There were significant differences in three dimensions among policemen with different academic qualifications. Job burnout decreased with the increase of academic qualifications, which was consistent with the results of Erickson, Ritter \&amp; Emotional (2001). Strong self-awareness is one of the reasons for burnout of low-educated policemen. The lower the educational background, the more they want to be recognized and accepted by the society, and the more urgent it is to improve their status and identity. In the activities of studying and practicing the scientific outlook on development carried out by the political and legal departments all over the country, more attention has been paid to the assessment of the professional quality of the police. Higher-educated individuals have higher and more comprehensive knowledge and theory, which makes them more outstanding in their work and assessment, so the higher their sense of self-achievement. Many policemen with low academic qualifications are not satisfied with the status quo, and the degree of job burnout is higher than that of policemen with high academic qualifications. Therefore, more attention should be paid to policemen with low academic qualifications when preventing and correcting job burnout. Highly educated policemen have a rational evaluation and understanding of the profession, which can avoid the occurrence of job burnout. For highly educated policemen, they are better able to use their own and external resources to take a more effective way to deal with pressure. For example, in interviews, when it comes to whether psychological pressure will lead to professional counseling, policemen with higher educational backgrounds express their desire to get professional help and to set up special counseling hotlines, while policemen with lower educational backgrounds can not fully accept this concept, which also reflects the psychological counseling for policemen. Importance of occupation

\section{The Influence AND InTERVEntion of Police JoB BURNOUT}

The consequences of job burnout are very serious. Burnout destroys their health, coping ability and life style. It also leads to the decline of individual job performance and affects the survival and development of the organization. First, it can lead to serious physical problems. When burnout occurs, the behavior of the police mainly includes excessive tension, unreasonable anxiety, physical and mental fatigue and insomnia. (Burke R J, 1993) [6]. Secondly, it will also affect work attitude and efficiency. Finally, burnout was positively correlated with police attitudes towards violence and their tendency to use violence at work. It can be seen that job burnout also has a considerable impact on the correctness, reasonableness and legality of police executive power(Kop N, Euwema M \& Schaufeli W ,1999) [7]. Job burnout is an important reason that affects the decision of the police to quit. Most policemen have the idea of "leaving the police post" because of mental exhaustion (Brown J , Cooper C\&Kirkcaldy $\mathrm{B}, 1996)$ [8], It reveals that burnout is closely related to job performance, absence rate and turnover rate, and that serious burnout will have a negative impact on the daily life of the police, resulting in professional, personal, family and social crises. (Zhensheng Zhang, Yonghong Xu, 2004)[9].

To effectively intervene in police job burnout, from the police's own point of view, the police should formulate practical goals, not excessively exceed their own abilities, high-minded and far-fetched, Work should be relaxed, find the right way to relax, rest and relax fully, and continue to learn, improve ability, so that they can grasp their own life; Institutionally, we should perfect the police's law enforcement power, establish and perfect the guarantee system of the police's right to appeal and accuse, earnestly safeguard the police's professional rights, fully consider the police's post characteristics and working functions, protect the police's personal safety, and establish a crisis intervention stress system; In police work, the unit gives the policeman a clear job description (job level, job summary, the duties performed, powers, performance standards), Only by making policemen understand why they should play a role and why they should be responsible can they have a clear goal and a good plan for their work[10]; In terms of social support, we should form a good atmosphere of public trust in the police profession, increase the support of the superior leaders of the public security organs, reduce the non-police activities of the police, optimize the law enforcement environment, and harmonize family relations.

\section{REFERENCE}

[1] Freudenberger, H. J. Staff Burnout[J].Journal of Social Issues 1974,30(1):159-165.

[2] Maslach C, Jackson SE. Measurement of experienced burnout[J]. The Journal of Occupational Behavior, 1981, 2:99-133.

[3] Zhenxing Gong. Police job burnout and its intervention. Journal of Liaocheng University.2008(2):183-184(In Chinese)

[4] Maslach C, Jackson S E,Leiter M P. Maslach Burnout Inventory (Third Edition). In Zalaquett C P., Wood R J. Evaluating Stress: A Book of Recourse [M]. M D\& London: The Scarecrow Press, Inc. Lanham. 1997

[5] Yongxin li, Mingzheng Wu. Structural research on Job Burnout [J]. Psychosocial Science,2005,28 (2):454-457.( In Chinese)

[6] Burke R. J. Toward an understanding of psychological burnout among police officers[J].Journal of Social Behavior and Personality, 1993, 8(3): $425-438$.

[7] Kop N,Euwema M,Schaufeli W. Burnout, job Stress and Violent behavior among Dutch police officers [J].work and Stress,1999 (4).

[8] Brown J, Cooper C, Kirkcaldy B. Occupational stress among senior police officers British Journal of Psychology [ J ]. 1996, 87.

[9] Zhensheng Zhang, Yonghong Xu. Analysis of job burnout of Chinese police [J] Journal of Chinese People's Public Security University, 2004, (3):130-134. (In Chinese)

[10] Guoming Qiu, A study on stressors, job burnout and work attitude of bank clerks [D]. Master's thesis, Institute of human resource management, national Zhongshan University.2001. (In Chinese) 